\title{
Loss of lung function associated with exposure to silica dust and with smoking and its relation to disability and mortality in South African gold miners
}

Eva Hnizdo

\begin{abstract}
The data from a lung function study on 2209 white 45-54 year old South African gold miners in 1968-71 and at a five year follow up examination, were analysed to establish the actual loss of lung function associated with exposure to silica dust and with smoking. Ex-smokers were excluded from the analysis. Of the remaining 1625 subjects, 1249 had the five year follow up test of lung function. The estimated excess loss of lung function for a 50 year old gold miner, associated with 24 years of underground dust exposure of an average respirable dust concentration of $0.30 \mathrm{mg} \mathrm{m}^{-3}\left(14.4 \mathrm{ghm}^{-3}\right)$ was $236 \mathrm{ml}$ of FEV $_{1}(95 \%$ confidence interval $(95 \%$ CI $134-$ $337)$ and $217 \mathrm{ml}$ of FVC (95\% CI 110-324). By comparison, the effect of smoking one packet of cigarettes a day over 30 years was associated with an estimated loss of $552 \mathrm{ml}$ of $\mathrm{FEV}_{1}(95 \%$ CI 461-644) and $335 \mathrm{ml}$ of FVC (95\% CI 170500). The cumulative dust exposure was not associated with the longitudinal loss of $\mathrm{FEV}_{1}$ or FVC when the initial $F_{1}$ and FVC were adjusted in the models. According to the predicted values, however, gold miners appear to have a greater loss of lung function from $\mathbf{5 0}$ to 55 years of age than that predicted for a general population.
\end{abstract}

In white South African gold miners chronic obstructive pulmonary disease (COPD) is a more important cause of disability and mortality than is silicosis. ${ }^{1-3}$ Since 1952, when COPD was made a compensatable disease, the compensation rate for COPD has progressively increased, especially for white miners.

Gold mining dust contains roughly $30 \%$ of free silica. ${ }^{4}$ There are two theories on how inhaled silica

Epidemiology Research Unit, Medical Bureau for Occupational Diseases, PO Box 4584, Johannesburg 2000, South Africa

E Hnizdo particles could be involved in a pathogenic process leading to COPD. Firstly, inhalation of small silica particles can cause fibrosis and thickening of small airway walls, thus increasing airflow obstruction. ${ }^{5}$ Secondly, silica particles can be engulfed by the alveolar macrophages, which then bring about the release of proteolytic enzymes that can cause the destruction of alveolar walls and eventually emphysema. ${ }^{6}$

Several epidemiological studies on South African gold miners found an association between impairment of lung function and increasing exposure to silica dust. ${ }^{378}$

This association was more likely to be due to the effect of silica dust itself on impairment of lung function, rather than the effect of silicosis in the lung ${ }^{9}$ (and Wiles FJ, Baskind E, Hessel PA, Hnizdo E, unpublished data). Other studies showed a significant association between exposure to silica dust and the degree of emphysema found at postmortem examination using paper mounted whole lung sections. ${ }^{1011}$ Finally, an increased mortality from COPD in the white miners (standardised mortality ratio $(\mathrm{SMR})=165 \cdot 6 ; 95 \%$ confidence interval $(95 \% \mathrm{CI})$ 108-243) was found to be related to increasing dust exposure. ${ }^{2}$

In a recent study of black South African gold miners the expected loss of lung function associated with 25 years of exposure to gold mining dust was estimated as $200 \mathrm{ml}$ of forced expiratory volume in one second $\left(\mathrm{FEV}_{1}\right){ }^{3}{ }^{3}$ The additional loss attributable to silicosis (category $2 / 2$ ) was estimated as $320 \mathrm{ml}$ of $\mathrm{FEV}_{1}$ and $234 \mathrm{ml}$ of forced vital capacity (FVC). None of the previous papers on white gold miners quantified the association between excess loss of lung function and exposure to gold mining dust. Because white gold miners generally have more reliable records of exposure to silica dust and of tobacco consumption than black miners, who are mostly migrant workers, the effect of the individual exposures on loss of lung function can be estimated with greater precision.

The objective of this paper is to report on a reanalysis of data on lung function collected on 2209 white South African gold miners in $1968-71,{ }^{8}$ and on 
an analysis of a five year follow up study that has not been previously published; in particular to quantify the loss of lung function attributable to exposure to silica dust and to smoking. The significance of the loss of lung function attributable to each exposure factor was assessed through comparisons with the predicted $\mathrm{FEV}_{1}$ curves estimated for a general non-mining population, and through the miners' disability and mortality data.

\section{Material and methods}

The study subjects comprised 2209 white gold miners who were studied in 1968-71 for respiratory impairments. ${ }^{8}$ The details of the original study are reported elsewhere; ${ }^{28912}$ and only a brief description will be given here. Miners who attended a compulsory annual medical examination during 1968 to 1971 were selected for that study if they fulfilled the following criteria: the Medical Bureau for Occupational Diseases (MBOD) file number was within the range of $\mathrm{B} 9000$ to $\mathrm{C} 8999$; their ages were between 45-54 years; they had had underground gold mining service of at least 10 years and less than two years of service in other mines; they had resided in South Africa for at least 20 years.

For the present study ex-smokers $(n=426)$ were excluded, as their smoking habits have greater variation and thus the effects of smoking and dust are more difficult to evaluate. Of the remaining 1783 miners, 158 were also excluded as their tests of lung function were rejected by a pulmonary physiologist as unsatisfactory during the 1968-71 study and were thus not recorded on the computer file. The 158 excluded miners, by comparison with the remaining 1625 miners whose lung function tests were acceptable, were slightly older $(50.8 v 50.1$ years; $p=0.0002)$, had higher cumulative exposure to dust $(15.3 v 14.4 \mathrm{~g}$ hours per $\left.\mathrm{m}^{3}\left(\mathrm{ghm}^{-3}\right) ; \mathrm{p}=0.02\right)$, but did not differ significantly in their body weight, height, or tobacco consumption. The 1625 miners included in this analysis constituted 232 never smokers and 1393 current smokers.

\section{FIVE YEAR FOLLOW UP LUNG FUNCTION STUDY}

Of the 1625 miners, 1249 had five year follow up tests of lung function. The follow up tests were obtained on miners who returned to MBOD for a medical examination. The reasons for their return were as follows: 681 came specifically for the follow up study, 480 came for an examination for compensation, and 88 came for a statutory periodical examination. Because the three groups of miners did not differ significantly in their measurements of lung function all the miners were included in the five year follow up study.

The average follow up time was 4.9 (SD $1 \cdot 7$; range 1-10) years. The average age at the follow up examination was 55 (SD 3.0; range 47-65) years. The 376 miners who did not have the follow up examination had lower values for lung function and exposure to dust at the 1968-71 examination by comparison with the other miners (see table 1). The tobacco consumption of the current smokers who did not have the follow up examination was not higher, but a significantly higher proportion of smokers than nonsmokers did not have the follow up examination.

ESTIMATION OF EXPOSURE TO SILICA DUST

The cumulative dust exposure was estimated in terms of respirable dust, measured as $\mathrm{ghm}^{-3}$. All the occupations of the gold mines were categorised into seven occupational categories for which the respirable dust concentrations were estimated in terms of respirable dust surface area (RSA) by Beadle et al.$^{4}$ The measurments in RSA $\left(\mu \mathrm{m}^{2} / \mathrm{cc}\right)$ (obtained after heat and acid treatment) were converted into mass of respirable dust (MRD) (the conversion equation was developed by $\mathrm{D}$ Rendall, personal communication). The relation was derived from data collected by the late D G Beadle in the course of underground dust surveys carried out on behalf of the then Pneumoconiosis Research Unit. The equation is conveniently expressed in the form MRD $=0.027 \times(\mathrm{RSA})^{0.474}$. This equation explains $76 \%$ of variation in RSA. The formula is applicable to the occupational group means. The error associated with the conversion from RSA over the range $100-1000 \mu \mathrm{m}^{2} / \mathrm{cc}$ is generally less than $0.1 \mathrm{mg} / \mathrm{m}^{3}$. The estimates of respirable dust mass in $\mathrm{mg} / \mathrm{m}^{3}$ were comparable with measurements obtained by gravimetric sampling from various surveys done in the gold mines.

The cumulative exposure to dust in $\mathrm{ghm}^{-3}$ was then calculated as a sum of products between the number of shifts spent in an occupational category, the average number of hours spent underground in each occupational category, and the average respirable dust concentration $\left(\mathrm{mg} / \mathrm{m}^{3}\right)$ for the occupational category, divided by 1000 . The cumulative exposure to dust was calculated up to the 1968-71 examination and for the follow up period. In a preliminary analysis of this data cumulative exposure to dust was a stronger predictor of the effect of mining exposure on loss of lung function than the duration of exposure to underground dust.

\section{SMOKING HABITS}

A smoking questionnaire was applied at the 1968-71 examination. The answers were checked against the smoking records kept in the medical files at MBOD. Several variables representing smoking habits were created. The smoking variables most strongly associated with loss of lung function were the variables representing the current smoking state $(0 / 1$ value) and cigarette equivalent pack-years. 
LUNG FUNCTION TESTS

For both examination periods the spirograms were measured on a Godart water sealed spirometer with the subject seated and wearing a noseclip. Three spirogram tracings were done on each subject and the best performed test was recorded. The lung function measurements analysed in this study were forced expiratory volume in one second $\left(\mathrm{FEV}_{1}\right)$, forced vital capacity (FVC), forced expiratory flow from $25 \%$ to $75 \%$ of expiratory volume $\left(\mathrm{FEF}_{25-75}\right)$ and peak expiratory flow (PEF).

\section{RADIOLOGICAL READINGS OF SILICOSIS}

The grade of silicosis was assessed by an experienced reader at the time of the 1968-71 study using radiograms taken during the 1968-71 examination.

\section{MORTALITY DATA}

The follow up period for the collection of mortality data was from the date of the 1968-71 examination to 30 December 1986. The death certificates were obtained from the Department of Interior. The causes of death were coded according to the ninth revision of the International Classification of Diseases (ICD) of the World Health Organisation by an independent physician using the best available information derived from the death certificate, necropsy report, and medical file of the MBOD. Of the 1625 miners included in the present study, 739 have died during the follow up period. Almost $85 \%$ of the deceased miners had a postmortem examination of the cardiorespiratory organs done at the National Centre for Occupational Health to establish if their dependants qualified for compensation because of pneumoconiosis or COPD.

\section{STATISTICAL ANALYSIS}

Multiple linear regression analysis was applied to identify the factors related to the longitudinal loss of lung function and to estimate the loss. The dependent variables analysed were: the individual lung function measurements for the 1968-71 and five year follow up examinations, and the longitudinal lossnamely, the difference between the two examination periods. The independent variables used were cumulative exposure to dust up to 1968-71 and after 1968-71, the current smoking state $(0 / 1)$, cigarette equivalent pack-years, age at the time of examination, body height and weight, and the grade of radiological silicosis. For the analysis of the longitudinal loss the lung function measurements in 1968-71, the duration of follow up, and the age at follow up were also included as independent variables. The stepwise method of variable selection was applied. Various interaction effects were tested by taking into account the criteria of goodness of fit. The best fitting parsimonious models are reported. All the lung function tests and the longitudinal loss were normally distributed.

For the comparison with the general non-mining population the $\mathrm{FEV}_{1}$ values were standardised to a height of $173 \mathrm{~cm}$ using the method suggested by Dockery et al ${ }^{13}\left(\mathrm{FEV}_{1} /\right.$ Height $\left.(\mathrm{cm})^{2} \times 173^{2}\right)$. The association between death from all causes and the individual measurements of lung function and the other confounding factors was estimated by the Cox's proportional hazards model in which the mortality follow up time was taken into consideration.

\section{Results}

Table 1 shows the characteristics of the 1625 miners and their average measurements of lung function. Table 2 shows the mean $\mathrm{FEV}_{1}$ values (standardised to a height of $173 \mathrm{~cm}$ ), according to several levels of dust and smoking for the two examination times. Figure 1 shows the decline in the mean $\mathrm{FEV}_{1}$ (standardised to a height of $173 \mathrm{~cm}$ ) with increasing concentrations of respirable dust according to the smoking habits and the two examination times.

Table 3 shows the prediction equations for the individual tests of lung function estimated from the data for the 1968-71 and five year follow up examinations. Only the dust and smoking coefficients are shown for the five year follow up. The cumulative exposure to dust up to the 1968-71 examination was a significant predictor of all the indices of lung function, except of the follow up PEF; this may be, however, because only 791 miners had the follow up PEF measured. The magnitude of the regression coefficients decreased only slightly for the 5 year follow up tests. Figure 1 shows the predicted $F E V_{1}$ curves for respirable dust. As the slopes for the nonsmokers and current smokers were not statistically different the common slopes are shown.

According to the prediction equation for the 1968-

Table 1 Characteristics at 1968-71 examination of the total group of 1625 miners

\begin{tabular}{|c|c|c|c|}
\hline \multirow{2}{*}{$\begin{array}{l}\text { Characteristics } \\
\text { at } 1968-71 \\
\text { examination }\end{array}$} & \multirow{2}{*}{$\begin{array}{l}\text { Total } \\
(n=1625) \\
\text { mean }(S E)\end{array}$} & \multicolumn{2}{|c|}{ Follow up lung function tests done } \\
\hline & & $\begin{array}{l}Y e s(n=1249) \\
\text { mean }(S E)\end{array}$ & $\begin{array}{l}\text { No }(n=376) \\
\text { mean }(S E)\end{array}$ \\
\hline $\begin{array}{l}\text { Age } \\
\text { Height (cm) } \\
\text { Weight (kg) } \\
\mathrm{FEV}_{1.0}(1) \\
\mathrm{FEF}_{25-75}(1 / \mathrm{s}) \\
\text { FVC (1) } \\
\text { PEF (1/s) } \\
\text { Gold mining (y) } \\
\text { CDE (ghm }{ }^{-3} \text { ) } \\
\text { Cigarette } \\
\text { equivalents } \\
\text { (pack-years) }\end{array}$ & $\begin{array}{c}50 \cdot 1(0 \cdot 1) \\
175.4(0.2) \\
80.7(0.3) \\
3.08(0.02) \\
2.68(0.03) \\
4.30(0.02) \\
45.4(0.3) \\
23.6(0 \cdot 1) \\
14.4(0.1)\end{array}$ & $\begin{array}{c}50 \cdot 1(0 \cdot 1) \\
175 \cdot 5(0 \cdot 2) \\
80.9(0 \cdot 3) \\
3.12(0.02) \\
2.73(0.03) \\
4.32(0.02) \\
45 \cdot 9(0 \cdot 3) \\
23 \cdot 8(0 \cdot 1) \\
14 \cdot 6(0 \cdot 1)\end{array}$ & $\begin{array}{c}50.2(0.1) \\
175.3(0.3) \\
80.3(0.7) \\
2.96(0.04)^{\star} \\
2.49(0.06)^{\star} \\
4.23(0.04)^{\star} \\
43.7(0.6)^{\star} \\
22.8(0.3)^{\star} \\
13.8(0.2)^{\star}\end{array}$ \\
\hline
\end{tabular}

$\star_{p}<0.05$ 
Table 2 Observed FEV, values, standardised to height of $173 \mathrm{~cm}$ according to dust concentrations and smoking for the two examination times

\begin{tabular}{|c|c|c|c|c|c|c|c|c|c|}
\hline \multirow{3}{*}{ 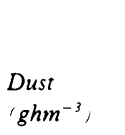 } & \multirow[b]{3}{*}{ Time } & \multicolumn{8}{|c|}{ Smoking category (pack-years) } \\
\hline & & \multicolumn{2}{|l|}{0} & \multicolumn{2}{|c|}{$1-<20$} & \multicolumn{2}{|c|}{$20-<40$} & \multicolumn{2}{|c|}{$\geqslant 40$} \\
\hline & & No & Mean $(S E)$ & No & $\operatorname{Mean}(S E)$ & No & $\operatorname{Mean}(S E)$ & No & Mean ( $S E$ ) \\
\hline \multirow[t]{2}{*}{$\leqslant 10$} & 1 & 51 & $3.64(0.06)$ & 52 & $3 \cdot 11(0 \cdot 10)$ & 123 & $3.05(0.07)$ & 67 & $3.02(0.08)$ \\
\hline & 2 & 42 & $3.40(0.08)$ & 36 & $2.80(0.13)$ & 89 & $2.71(0.08)$ & 44 & $2.78(0.09)$ \\
\hline $10-<15$ & 1 & 78 & $3.46(0.07)$ & 130 & $2.98(0.06)$ & 292 & $2.96(0.04)$ & 136 & $2.93(0.06)$ \\
\hline & 2 & 64 & $3.10(0.09)$ & 100 & $2.65(0.07)$ & 218 & $2.59(0.05)$ & 103 & $2.48(0.07)$ \\
\hline \multirow[t]{2}{*}{$15-<20$} & 1 & 71 & $3.26(0.07)$ & 110 & $3.06(0.06)$ & 205 & $2.78(0.04)$ & 93 & $2.70(0.07)$ \\
\hline & 2 & 61 & $3.03(0.07)$ & 90 & $2.81(0.07)$ & 156 & $2.48(0.05)$ & 69 & $2.44(0.07)$ \\
\hline \multirow[t]{2}{*}{$\geqslant 20$} & 1 & 32 & $3.51(0.11)$ & 41 & $2.87(0.09)$ & 111 & $2.81(0.06)$ & 33 & $2 \cdot 64(0 \cdot 10)$ \\
\hline & 2 & 29 & $3.29(0.11)$ & 33 & $2.55(0.11)$ & 87 & $2.53(0.07)$ & 28 & $2.36(0.12)$ \\
\hline
\end{tabular}

$1=1968-71$ examination; 2 = 5 year follow up examination.

71 examination the estimated loss of lung function attributable to dust exposure, for a 50 year old miner exposed to the average cumulative exposure to dust of $14.4 \mathrm{ghm}^{-3}$, was $236 \mathrm{ml}$ of $\mathrm{FEV}_{1}(95 \%$ CI 135 338 ) and $217 \mathrm{ml}$ of FVC (95\% CI 110-324). For the miners in the highest dust exposure quartile $\left(22 \cdot 2 \mathrm{ghm}^{-3}\right)$ the estimated loss attributable to dust was $364 \mathrm{ml}$ of $\mathrm{FEV}_{1}(95 \% \mathrm{CI} 207-521)$ and $335 \mathrm{ml}$ of FVC $(95 \%$ CI 170-500). The average actual duration of underground dust exposure for these miners was 24 years and the average concentration of respirable dust in the underground air was $0.30 \mathrm{mg} \mathrm{m}^{-3}$.

The significant losses of $\mathrm{FEV}_{1}$ attributable to the smoking effect were: the loss due to being a current smoker, which was $435 \mathrm{ml}$ (95\% CI 319-551), and the additional loss of $3.85 \mathrm{ml}(95 \% \mathrm{CI} 1.50-6.25)$ for each cigarette equivalent pack-year. Thus the estimated loss of $\mathrm{FEV}_{1}$ in a 50 year old current smoker with a smoking history of 30 pack-years was
$552 \mathrm{ml}(95 \% \mathrm{CI} 461-644)$. For a 50 year old current smoker with a smoking history of 60 pack-years the estimated loss of $\mathrm{FEV}_{1}$ was $689 \mathrm{ml}(95 \%$ CI 461-877). The loss of FVC associated with 30 packyears was $392 \mathrm{ml}$. The multiple linear regression analysis indicated that the effects of dust and smoking on the loss of $\mathrm{FEV}_{1}$ are additive. Thus the expected loss of $\mathrm{FEV}_{1}$ for a 50 year old currently smoking miner who worked in high dust occupations $\left(22.2 \mathrm{ghm}^{-} 3\right)$, with a smoking history of 30 cigarette equivalent pack-years, is $916 \mathrm{ml}$ (95\% CI 784 1042). These estimates are in accord with the data shown in figure 1 and in table 2.

To show the importance of the loss of lung function attributable to each of the two risk factors, the predicted $\mathrm{FEV}_{1}$ values for the miners were compared with those of a general male population estimated by Dockery et al. ${ }^{13}$ In fig 2 the predicted $\mathrm{FEV}_{1}$ values for the gold miners, derived from the

Table 3 Prediction equations for $F E V_{1}, F V C, F E V_{1} / F V C, F E F_{25-75}$, and PEF for the $1968-71$ and 5 year follow up examinations

\begin{tabular}{|c|c|c|c|c|c|}
\hline \multirow[b]{2}{*}{ Variable } & \multicolumn{5}{|c|}{ Lung function measurement } \\
\hline & $\begin{array}{l}F E V_{1} \\
\beta(S E)\end{array}$ & $\begin{array}{l}F V C \\
\beta(S E)\end{array}$ & $\begin{array}{l}F E V_{1} / F V C \% \\
\beta(S E)\end{array}$ & $\begin{array}{l}F E F_{25-75} \\
\beta(S E)\end{array}$ & $\begin{array}{l}P E F \\
\beta(S E)\end{array}$ \\
\hline \multicolumn{6}{|c|}{ 1968-71 examination } \\
\hline $\begin{array}{l}\text { Intercept } \\
\text { Age } \\
\text { Height (cm) } \\
\text { Weight }(\mathbf{k g}) \\
\text { CDE (ghm }{ }^{-3} \text { ) } \\
\text { Cigarette equivalents } \\
\text { (pack-years) }\end{array}$ & $\begin{array}{c}(n=1625) \\
-0.859(0.596) \\
-0.0354(0.0068) \\
0.0366(0.0027) \\
\text { NS } \\
-0.0164(0.0036) \\
-0.0039(0.0012)\end{array}$ & $\begin{array}{l}(\mathrm{n}=1625) \\
-2.440(0.616) \\
-0.0370(0.0070) \\
0.0521(0.0028) \\
\text { NS } \\
-0.0151(0.0038) \\
-0.0026(0.0012)\end{array}$ & $\begin{array}{l}(n=1625) \\
112.4 \\
-0.2206(0.0993) \\
-0.2025(0.0464) \\
0.1520(0.0231) \\
-0.1578(0.0532) \\
-0.0563(0.0172)\end{array}$ & $\begin{array}{c}(n=1625) \\
-2.138(0.679) \\
-0.0434(0.1176) \\
0.0188(0.0055) \\
0.0081(0.0027) \\
-0.0291(0.0063) \\
-0.0083(0.0020)\end{array}$ & $\begin{array}{l}(n=1605) \\
24.50(9.39) \\
-0.4365(0.1066) \\
0.2936(0.0430) \\
\text { NS } \\
-0.2783(0.0570) \\
-0.0645(0.0180)\end{array}$ \\
\hline $\mathbf{r}^{2}$ & $\begin{array}{l}-0.4352(0.0593) \\
0.21\end{array}$ & $\begin{array}{l}-0.3141(0.0618) \\
0.23\end{array}$ & $\begin{array}{l}-3.5350(0.8914) \\
0.09\end{array}$ & $\begin{array}{l}-0.7089(0.1052) \\
0.14\end{array}$ & $\begin{array}{l}-3.7625(0.9341) \\
0.10\end{array}$ \\
\hline \multicolumn{6}{|c|}{ Five year follow up examination } \\
\hline $\begin{array}{l}\text { Estimated means } \\
\text { CDE (ghm }{ }^{-3} \text { ) } \\
\text { Cigarette equivalent } \\
\quad \text { (pack-years) }\end{array}$ & $\begin{array}{l}(n=1249) \\
3.405 \\
-0.0146(0.0043) \\
-0.0061(0.0014)\end{array}$ & $\begin{array}{l}(n=1249) \\
4 \cdot 410 \\
-0.0134(0.0045) \\
-0.0022(0.0014)\end{array}$ & $\begin{array}{c}(n=1249) \\
76 \cdot 552 \\
-0 \cdot 1160(0.0699) \\
-0.1034(0.0229)\end{array}$ & $\begin{array}{l}(n=1249) \\
3.312 \\
-0.0244(0.0068) \\
-0.0106(0.0022)\end{array}$ & $\begin{array}{l}(n=791) \\
48 \cdot 026 \\
\text { NS } \\
-0.0904(0.0352)\end{array}$ \\
\hline $\mathrm{S}_{\mathrm{r}^{2}}$ & $\begin{array}{l}-0.4112(0.0695) \\
0.17\end{array}$ & $\begin{array}{l}-0.3145(0.0716) \\
0.18\end{array}$ & $\begin{array}{l}-3.4354(1 \cdot 1539) \\
0.10\end{array}$ & $\begin{array}{l}-0.6173(0.1104) \\
0.15\end{array}$ & $\begin{array}{l}-3.2563(1.7889) \\
0.22\end{array}$ \\
\hline
\end{tabular}




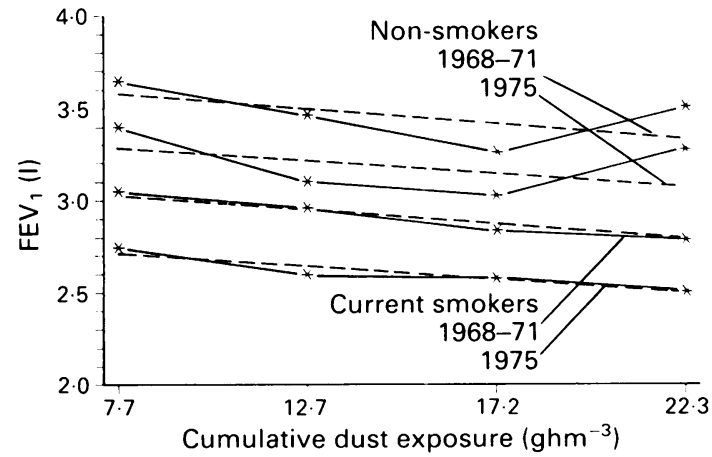

Figure 1 Mean FEV, values, standardised to height of $173 \mathrm{~cm}$, plotted against respirable dust, according to smoking habits, for 1968-71 and five year follow up examination. The solid line shows the observed data and the dashed lines shows the predicted slope.

two equations in table 2 , for 50 and 55 years of age respectively, were projected on to the expected $\mathrm{FEV}_{1}$ curves for a $173 \mathrm{~cm}$ tall man who is not a miner, who does not smoke (A), who smokes one pack a day starting at 25 years of age (B), and who smokes two packs a day starting at 25 years of age (C) ${ }^{13}$ The observed height adjusted $\mathrm{FEV}_{1}$ for smoking and nonsmoking miners 20 and 30 years of age obtained from a longitudinal study done in 1970 s are also shown (D).$^{14}$ The younger miners had higher FEV values than those expected in the non-miners, indicating that the miners were generally fitter men to start with than the general population; however, by 50 years of age the miners with an average one pack a day tobacco consumption already had lower estimated FEV

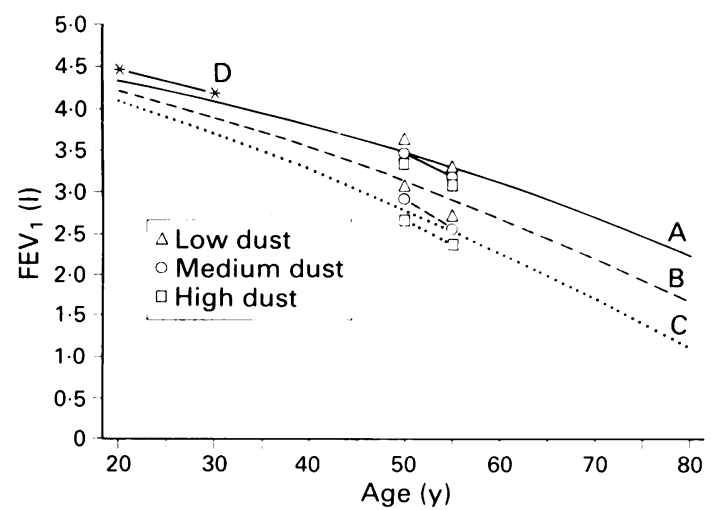

Figure 2 Predicted FEV, values for gold miners, according to dust exposure and smoking, projected on to predicted curves for non-miners. ( $A$ ) non-smokers; (B) current smokers of one pack a day, and (C) current smokers of two packs a day. The curve (D) shows the mean observed FEV, values for 20 and 30 year old white South African gold miners, smokers, and non-smokers.

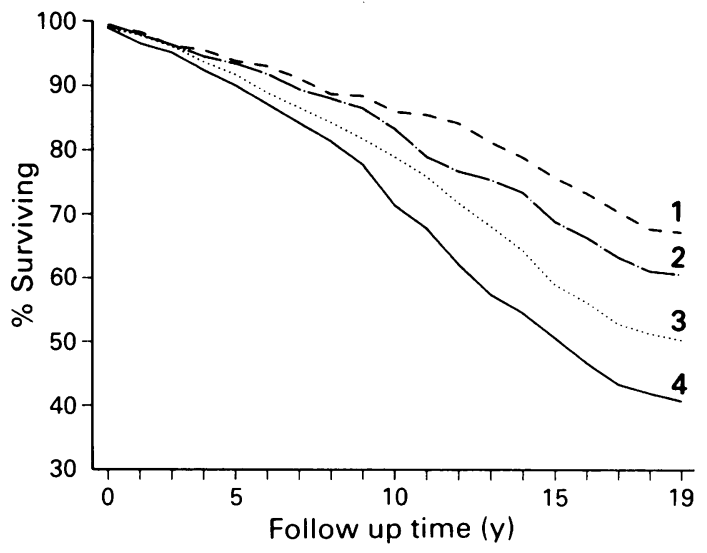

Figure 3 Percentage of $50( \pm 2.5)$ year old gold miners surviving during 17 years of mortality follow up according to their initial FEV, quartiles.

values compared with the non-miners. The miners with an average tobacco consumption of two packs a day and with high dust exposure had substantially lower $\mathrm{FEV}_{1}$ than the non-miners. The non-smoking miners in the highest dust concentration had better $\mathrm{FEV}_{1}$ than non-miners smoking one pack a day.

The five year follow up predicted $\mathrm{FEV}_{1}$ values (for 55 years of age) indicated that the miners had a steeper decline in lung function than the non-miners. The analysis of the longitudinal loss did not, however, show that cumulative exposure to dust was related to the longitudinal loss of $\mathrm{FEV}_{1}$ or FVC, when the initial (1968-71) values were adjusted for. The variables significantly related to the longitudinal loss were the initial (1968-71) lung function value, cigarette equivalent pack-years, the current smoking state in 1968-71, and the years of follow up, in that order. This result is in accord with figure 1 .

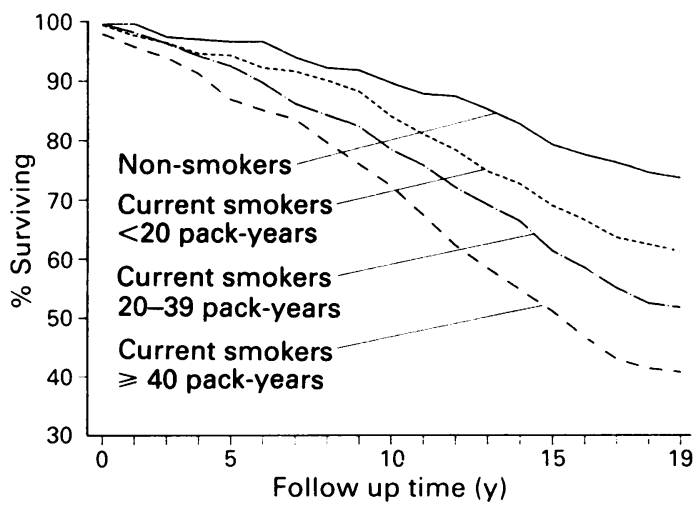

Figure 4 Percentage of $50( \pm 2 \cdot 5)$ year old gold miners surviving during 17 years of mortality follow up according to smoking habits at 50 years of age. 


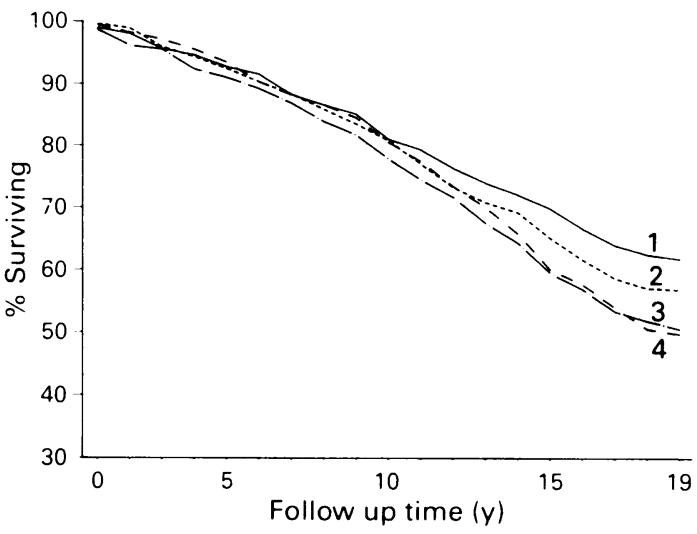

Figure 5 Percentage of $50( \pm 2 \cdot 5)$ year old gold miners surviving during 17 years of mortality follow up according to quartiles of respirable dust cumulated to 50 years of age.

The results from the Cox's proportional hazards model indicated that of all the lung function tests, the $\mathrm{FEV}_{1}$ was most strongly associated with mortality from all causes. Figure 3 shows how seriously the $\mathrm{FEV}_{1}$ value, found in 1968-71, affects the chances of survival of a 50 year old miner during the next 17 year period. To show which of the two risk factors contributed more to the overall mortality, the survival according to amounts of smoking (fig 4), and concentrations of dust (fig 5) are also shown. The presence and degree of radiological signs of silicosis were not associated with mortality from all causes.

\section{Discussion}

LOSS OF LUNG FUNCTION ATTRIBUTABLE TO DUST AND SMOKING

The results from the present analysis indicate that exposure to silica dust in South African gold mines is associated with a significant loss of lung function. The expected excess loss of lung function for a 50 year old miner exposed for 24 years to underground dust with an average respirable dust concentration of $0.30 \mathrm{mgm}^{-3}$ (cumulative exposure to dust of about $\left.14 \cdot 4 \mathrm{ghm}^{-3}\right)$ is $236 \mathrm{ml}$ of $\mathrm{FEV}_{1}$, (95\% CI 134-337) and $217 \mathrm{ml}$ of FVC (95\% CI 110-324). The loss of $\mathrm{FEV}_{1}$ attributable to the average exposure to dust was slightly less than half of that associated with smoking of one pack a day over 30 years. Of all the detrimental factors related to the loss of lung function the current smoking state was associated with the highest loss of lung function.

According to predicted values the non-smoking miners in the highest quartile of dust exposure were better off than the current smokers of one pack a day in the general population (fig 2). The smoking miners had much lower lung function, however, than the smoking non-miners. The predicted $\mathrm{FEV}_{1}$ values for the five year follow up study ( 55 years of age) indicate that the gold miners have a steeper slope with age than the non-miners. Because the miners who did not have a follow up examination had on average lower lung function measurements than the miners included in the follow up study (table 1), it is unlikely that the loss of lung function was overestimated. When the miners who came for the compensation examination were excluded from the follow up data analysis, the mean values for the lung function values changed only slightly and the estimated coefficient for dust became slightly more negative.

The longitudinal loss of $\mathrm{FEV}_{1}$ was not, however, related to cumulative exposure to dust. The two most significant factors were initial $\mathrm{FEV}_{1}$ and cigarette equivalent pack years in 1968-71. This may be because most of the miners retired from dusty occupations in the early 1970s, whereas most of those who were current smokers in 1968-71 continued to smoke.

Of the measurements of lung function analysed for the association with exposure to silica dust, the PEF measured in 1968-71 was most strongly associated with the exposure. The contribution of exposure to dust towards the decrease in the individual lung function measurements, relative to the contribution of tobacco smoking, was about $41 \cdot 1 \%$ for PEF, $35.5 \%$ for FVC, $30.3 \%$ for $\mathrm{FEF}_{25-75}$, and $29.8 \%$ for $\mathrm{FEV}_{1}$ when the average exposures of cumulative exposure to dust $\left(14.4 \mathrm{ghm}^{-3}\right)$ and pack-years (30) were considered.

These results indicate that the contribution of tobacco smoking is substantially higher than the contribution of dust. The effect of silica dust in addition to the effect of tobacco smoking, however, has a potential to cause serious disability, which can lead to increased mortality. Silicosis was not a significant predictor of any of the measurements of lung function except of $\mathrm{FEV}_{1}$ in the non-smokers.

\section{CONTRIBUTION OF DUST AND SMOKING TO SERIOUS} RESPIRATORY DISABILITY

In another study done on the 2209 white gold miners the relative contribution of dust and smoking to the serious respiratory disability was evaluated..$^{12}$ There were 402 miners with appreciable obstructive impairment. It was estimated, using the aetiological fraction estimation, that approximately $8 \%$ of these cases were associated with the effect of dust only, $42 \%$ with smoking only, and $40 \%$ with the combined effect of dust and smoking; the remaining $10 \%$ were associated with an unknown effect. Of the 402 there were 191 cases with pronounced obstruction and restriction. It was estimated that $0 \%$ of these cases were associated with dust only, $39 \%$ with smoking only, $52 \%$ with the combined effect of dust and smoking, and the remaining $9 \%$ with an unknown effect. These results suggest (1) that exposure to silica 
dust alone is rarely associated with a serious respiratory disability in persons who are fit enough to become full time miners, whereas smoking alone can cause a serious disability in these persons; (2) that in the gold miners the combined effect of dust and smoking is responsible for a large proportion of cases with serious disability, (3) that elimination or reduction of tobacco smoking would prevent most of the cases with serious disability in the white gold miners; and (4) that a reduction in exposure to dust would also reduce by a substantial number the cases who were mostly associated with the combined effect of dust and smoking.

CONTRIBUTION OF DUST AND SMOKING TO MORTALITY The white South African gold miners have a higher mortality from COPD than the general white South African population $(\mathrm{SMR}=165 \cdot 6,95 \%$ CI 108 243). ${ }^{1}$ When the relative contribution of dust and smoking to mortality from COPD was examined it was estimated that approximately $34 \%$ of the cases who died from COPD were associated with smoking only, $59 \%$ of the cases were associated with the combined effect of dust and smoking, $5 \%$ with dust only (the $5 \%$ was due to one miner who did not smoke cigarettes but was a life long pipe smoker). ${ }^{2}$ Even though the aetiological fractions have a large error attached to them, they give some indication of the magnitude of the effects. For example, the good agreement between the figures for the pronounced obstructive impairment with restriction and mortality from COPD is to be expected as $13 \%$ of those miners died from COPD.

Of all the individual measurements of lung function analysed, the $\mathrm{FEV}_{1}$ was the strongest predictor of mortality from all causes. Figure 3 shows the effect of $\mathrm{FEV}_{1}$ quartiles on the survival during the 17 year mortality follow up period. The main "external" risk factors associated with low FEV were tobacco smoking and exposure to silica dust. Figures 4 and 5 show the survival rate according to cigarette equivalent pack-years categories and quartiles of silica dust. The effect of tobacco consumption on survival was bigger than that of dust. Exposure to dust was related to deaths from pulmonary tuberculosis, lung cancer, chronic obstructive lung disease, and nephritis, whereas a low $F E V_{1}$ value was related to most of the main categories of causes of deaths. A large proportion of the deaths were from diseases related to lifestyle: $49 \%$ of miners died from cardiovascular diseases, $21 \%$ from non-malignant respiratory diseases, and $8 \%$ from lung cancer.

It should also be mentioned that six of the nonsmokers included in this study were compensated because of COPD on the basis of their lung function tests. At necropsy examination, however, all were found to have an insignificant degree of emphysema and only one miner had moderate gland hyperplasia in the bronchioles. All six miners were very obese and suffered from coronary heart disease. It is suspected that general lack of fitness and coronary heart disease may be a contributing factor in the loss of lung function in these white gold miners.

A recent study on black South African gold miners ${ }^{3}$ indicated that the loss of lung function attributable to exposure to gold mining dust may be greater in black than in white miners. The estimated loss of $\mathrm{FEV}_{1}$ attributable to 25 years of underground mining exposure was $200 \mathrm{ml}$ and the additional loss due to silicosis (category 2/2) was $320 \mathrm{ml}$; however, the study could have overestimated the effect of silicosis on the loss of lung function. ${ }^{15}$ Other evidence indicates that black miners do not have such a high occurrence of COPD as white miners. Firstly, substantially fewer black miners are compensated for disability from COPD. Of 773 white miners who were certified for disability in $1987,31 \%$ were because of COPD. Of 2414 black miners certified in 1987 , only $2 \%$ were because of COPD. Secondly, few black miners have a noticeable degree of emphysema at necropsy examination. Of the 34140 necropsies on black miners $1.6 \%$ had moderate emphysema and only $0.04 \%$ had pronounced emphysema; whereas, of the 12748 necropsies on white miners, the figures were $19.0 \%$ and $1.6 \%$ respectively. If, however, silicosis per se is responsible for the loss of lung function in the black miners then the black miners would be compensated for silicosis rather than COPD and in this case emphysema may not be so common in these miners. The other possibilities are that in black gold miners, who have on average substantially lower tobacco consumption than white miners, ${ }^{312}$ the exposure to silica dust may cause small airways obstruction rather than emphysema and that the effect of silicosis may be more detectable.

Many questions arise from the two studies on the South African gold miners: (1) Does silica dust exposure in South African gold mines cause serious respiratory disability in black gold miners? (2) Does the loss of lung function associated with exposure to dust result in an increased mortality from COPD in black gold miners? (3) Is the underlying physiological cause of loss of lung function in gold miners, silicosis, airways obstruction, or emphysema? (4) How are gold miners to be persuaded that the combined effect of dust and smoking is destructive to their health and that they should reduce their smoking? (5) Is it possible to determine a safe concentration of silica dust in the underground air in terms of loss of lung function when the combined effect of silica dust and smoking appears to be most deterimental?

I thank Dr D C F Muir from the Occupational Health Program, McMaster University, Canada, as 
it was his interest in the issue which encouraged me to write the paper, D Rendall for his help with the conversion of dust factors, and Dr E Baskind for his helpful comments.

1 Wyndham $\mathrm{CH}$, Bezuidenhout BN, Greenacre MJ, SluisCremer GK. Mortality in middle aged South African gold miners. Br J Ind Med 1986;43:677-84.

2 Hnizdo E. Combined effect of silica dust and tobacco smoking on mortality from chronic obstructive lung disease in gold miners. Br J Ind Med 1990;47:656-64.

3 Cowie RL, Mabena SK. Silicosis, chronic airflow limitation, and chronic bronchitis in South African gold miners. Am Rev Respir Dis 1991;143:80-4.

4 Beadle DG, Harris E, Sluis-Cremer GK. The relationship between the amount of dust breathed and the incidence of silicosis: an epidemiological study of South African European gold miners. In: Shapiro HA, ed. Pneumoconiosis: proceedings of the international conference, Johannesburg, 1969. Cape Town: Oxford University Press, 1970;473-7.

5 Churg A, Wright JL, Wiggs B, Pare PD, Lazar N. Small airways disease and mineral dust exposure. Prevalence, structure, and function. Am Rev Respir Dis 1985;131:139-43.

6 Churg A, Hobson J, Wright J. Functional and morphological comparison of silica - and elastase-induced airflow obstruction. Experimental Lung Research 1989;15:813-22.

7 Becklake MR, duPreez L, Lutz W. Lung function in silicosis of the Witwatersrand gold miners. American Review of Tuber- culosis 1958;77:400-12.

8 Wiles FJ, Faure MH. Chronic obstructive lung disease in gold miners. In: Walton WH, ed. Inhaled particles IV, Part 2. Oxford: Pergamon Press, 1977;727-35.

9 Irwig LM, Rocks P. Lung function and respiratory symptoms in silicotic and nonsilicotic gold miners. Am Rev Respir Dis 1978; 117:429-35.

10 Becklake MR, Irwig L, Kielkowski D, Webster I, De Beer M Landau S. The predictors of emphysema in South African gold miners. Am Rev Respir Dis 1987;135:1234-41.

11 Hnizdo E, Sluis-Cremer GK, Abramowitz JA. Emphysema type in relation to silica dust exposure, in South African gold miners. Am Rev Respir Dis 1991;143:1241-7.

12 Hnizdo E, Baskind E, Sluis-Cremer GK. Combined effect of silica dust exposure and tobacco smoking on the prevalence of respiratory impairments among gold miners. Scand J Work Environ Health 1990;16:411-22.

13 Dockery DW, Speizer FE, Ferris BG, Ware JH, Louis TA, Spiro A. Cumulative and reversible effects of lifetime smoking on simple tests of lung function in adults. Am Rev Respir Dis 1988;137:286-92.

14 Irwig LM. Correction for the effect of measurement error on the association between environmental exposure and respiratory impairment. Johannesburg: research report No 1, 1986.

15 Hnizdo E, Hessel PA, Sluis-Cremer GK. Chronic airflow limitation in South African gold miners. Letter to the editor. Am Rev Respir Dis 1991;144:1423-4.

Accepted 4 November 1991 